\title{
Introduction: At the Sharp-End of Globalisation and Demographic Change
}

Much has been written about the changing fortunes of the generations following the baby-boomer generation born between 1945 and 1965 . Most in the spotlight have been the Millennials who were born after 1979, grew up during the Thatcher years, and who came to adulthood in the late 2000s, many entering the labour market at the time of the 2008 financial crisis and ensuing recession and austerity. They have been variously labelled the 'lost generation', the 'jilted generation', the 'wasted' generation, 'stagnation generation' and 'generation rent', pointing to their relative disadvantages as a generation born at a bad time. ${ }^{1}$ This generation of young people were not only harder hit than other age groups by the Great Recession; they are also experiencing the effects of longerterm structural changes, many of whose origins predated the crisis, and some of which may impact on opportunities well into the future. These include changes in the nature of work, the crises in housing and pensions and, most recently, the ramifications of the UK Brexit referendum vote, which most young people did not support. It is widely held that they face more limited opportunities than their parents and may be the first generation to do so since those born at the start of the last century. ${ }^{2}$

These conditions are often said to be changing the pattern of transitions young people make into adult life. They are living at home with their parents for longer and taking more time to achieve financial independence; they are buying houses later, if at all; and they are taking longer to achieve stable jobs, especially ones which match their qualifications. ${ }^{3}$ They are also marrying later and having their first child later, 
a trend which some say delays their assumption of adult civic roles and responsibilities. ${ }^{4}$ Most of the traditional markers of adult status seem harder to achieve than they were.

The effects of these changes on young people's attitudes and behaviors are also much debated. In the traditional media stereotypes, young people have become increasingly 'disengaged', 'apathetic' and 'cynical.' They show a increasing distrust of politicians and mainstream politics and an aversion to voting in elections which has been rising, albeit unevenly, since the late 1980s. In more complex accounts they are seen as an increasingly isolated generation, who lack the institutional supports of previous generations and feel they must face their difficulties alone. They have a tendency to turn inwards and, as in Jennifer Silva's study of young working-class Americans, often struggle to manage their internal 'mood economy' simply to get by. ${ }^{5}$ On another account, they are a generation of pragmatists, who know the generational dice are stacked against them and who are seeking new ways to advance their lives and make their voices heard.

Although much has been written about the conditions of young people today, many questions remain under-explored, particularly those relating to longer-term shifts in the relations between generations. Amongst the most salient of these questions are:

- How far and in what life domains have opportunities for the current generation of youth diminished relative to previous generations? Do the positive generational gains in opportunities in some spheres, like education and lifestyle choices, offset the apparently negative changes in other spheres, like housing and pensions? What is the overall balance sheet of life chances for this generation compared with previous ones?

- Are all young people affected, or is this group of young people so socially differentiated that we cannot speak meaningfully about a generational shift?

- If there has been a major shift affecting young people as a whole, is it one which will impact on the entire life course of this generation (a genuine cohort effect/generational shift)? Or is it more of a temporary dislocation, whereby historical circumstances at a particular time have impacted disproportionately on one age group-those who were coming of age at the time of the financial crisis-thus 
delaying their transitions to adult life, but not permanently changing the course of their lives?

- If this is a genuine generational shift, affecting opportunities throughout the life course, how far into do we see it extending into the future? Will this generation be a one-off 'lost generation', disadvantaged throughout their collective life time, but followed by new generations which fare better? Or are we facing a succession of generations, each made worse off than the ones preceding by ongoing uni-directional changes in economy, society and culture-a scenario which reverses the notions of historical progress through successive generations to which we have been accustomed for two centuries?

- How would young people and older adults—and indeed the political establishment itself-respond to a 'world in reverse gear' and would their responses change the pattern? The electoral dominance of the 'grey vote' will continue, but what new political alliances may emerge if an unlucky youth cohort carry their disadvantages into middle age, sharing common problems with the generation which comes after them?

These questions are, of course, hard to answer because they require us to look into the future. The best we can do is to extrapolate from current trends, factoring in different contingencies, and remembering that history rarely follows a straight path. Nevertheless, it is notable how little common ground exists on these issues, either in the research literature or in public opinion. By no means everyone agrees that young people today are actually worse off than previous generations of youth, and many of those who do consider it just a temporary phenomenon. To many social class differentiation amongst young people renders discussions of generational differences questionable anyway.

To date, systematic analysis of these issues has been quite limited, despite the plethora of commentary on the current plight of young people. There has also been surprisingly little sustained debate about what should be done to address generational disadvantages, even in the areas where these are most apparent. Even within the writings of the most pessimistic 'generational declinists' there is a startling absence of discussion about actual policies for improving generational equity. We have yet to see anything like an equal rights movement for young people to match the campaigns for gender and race equality of the 1960s and 1970s. Within mainstream politics, governments generally require policy-makers 
to assess the impact of new policies on gender and ethnic equality, but no such principle applies for generational equity.

This book focuses on generational changes in opportunities and life chances in the UK, rather than on the attitudes and behaviours of young people themselves. It seeks to advance the debate by exploring the questions above across the key life and policy domains affecting young people's opportunities, including education, work, housing and welfare. The final three chapters propose a range of policies for enhancing intergenerational equity, whilst considering the political conditions which might make such changes possible.

\section{The Drivers of Changes in Opportunities for Young PEOPle}

The existing literature provides very different perspectives on how we should interpret the changes in opportunity structures experienced by young people. However, accounts generally agree on the broad social and economic forces, both long-term and more conjunctural, which are behind the what we call the 'crisis for youth.' The main drivers of the changing opportunities have been demographic change, globalisation and the financial crisis and subsequent austerity.

Demographics. Populations are ageing due to greater longevity and a period of declining birth rates between the mid 1960s and 2000s. In the century from 1910/1912 to 2010/2012 life expectancy at birth in England increased for males from 51 to 79 years, and for females from 55 to 83 years. ${ }^{6}$ It is expected to rise further by 2032 , to 83 years for men and 87 years for women. One projection for 2061 has males living an average 87 years and females 90 years. ${ }^{7}$

While the population in Britain under 44 has remained relatively stable since the 1970s, the older population has increased dramatically, not only from people living longer, but also as the exceptionally large babyboomer generation is now reaching older age. ${ }^{8}$ The two trends are leading to an overall ageing of the population which is likely to reach a new peak around 2030 when the large baby-boomer generation are in their 80 s. $^{9}$ In 1971 the over 60 s represented 20 percent of the population; it is estimated that by 2030 a third of the population will be over 65 . The Office for National Statistics (ONS) predict that the number of people over the state pension age (taking account of the gradual raising of this) 
will increase between 2012 and 2037 by 31 percent, while those of working age will only rise by only 12 percent. Even with later retirement ages, the so-called age-dependency ratio-the number of working age divided by the number of pensioners-will decline from $3.2: 1$ in 2012 to $2.7: 1$ in 2037. ${ }^{10}$

Demographic ageing presents a challenge to economic growth generally, as the portion of the population who produce and (traditionally) consume most declines relative to the 'dependent' population of older people and children who produce and consume less in the market but rely more on state welfare services. It also presents a major challenge for intergenerational equity. Welfare states are designed to smooth out risks across the life course. ${ }^{11}$ State welfare resources are disproportionately devoted to the young and the old because they need them most. However, the system is based on a social contract which assumes that those who are at prime working age, and contribute most through taxes to the welfare state, will gain their reward when they are old and need to take out more. Over the life course each generation is meant to benefit equally from the ways state resources are distributed. Unfortunately, this system appears to be breaking down. ${ }^{12}$ Older people are taking up a growing proportion of state resources in health care and pensions (with the 80 percent of social/ benefit spending devoted to pensions and health care-which mostly goes on older people-being the most rapidly increasing area of public spending). The costs are being borne by younger tax payers, with the accumulated shortfall, the growing public debt, passed on to future generations.

Under the traditional intergenerational welfare contract, the tax contributions and welfare receipts of each generation would even out over the life course. But his seems unlikely to happen with the current young generation. They are likely to be paying higher taxes than the previous generation to cover the growing costs of state welfare spending and debt servicing. However, by the time they are old they are unlikely to see the same benefits in pension entitlements (either from state or private pensions) and unlikely to have the same level of health provision. Unlike the previous generation, they will not have the accumulated wealth from housing asset inflation to fall back on if their pensions cannot keep them adequately in old age.

Whether the generational inequalities resulting from demographic change affect future generations of young people depends partly on what happens to demographic change in the future which we cannot know for 
sure. Some predict that longevity will decline at some point (not least with increasing health problems associated with obesity amongst the younger cohorts). However, the normal assumption is that life expectancy will continue to increase. The secular trend in birth rates seems to be downward, even though some minor bulges in youth birth cohorts may emerge, partly as a result of marginally higher fertility rates from a growing immigrant population (as with those born after 2000 in the UK). However, high age-dependency ratios are likely to continue in developed countries for the foreseeable future. Legislation on later retirement will slightly offset the growth in the net costs to the state of older cohorts, but not enough to restore the previous intergenerational balance in contributions and spending. ${ }^{13}$

What does this mean for intergenerational inequalities going into the future? The disproportionate financial burdens on young and mid-life adults are likely to continue into the future. Future young generations may face the same problems. But there are different perspectives implicit in the accounts that focus on the long-term results of population ageing, and those which focus on specific cohort size effects. A focus on the ongoing process of rising life expectancy and consequent ageing populations suggests that each future generation of youth will be increasingly disadvantaged by the process, in the absence of political action to counteract it. A focus on particular on specific cohorts (and their relative sizes) shifts the perspective somewhat. In David Willetts' account the post-war baby boom-generation was unusually large, and their effects on intergenerational imbalances have been particularly significant. ${ }^{14}$ However, subsequent birth cohorts have all been smaller and consequently have less political power. This suggests that the extreme intergenerational imbalances of the present diminish in the future as increasing longevity is offset by the effects of smaller and less powerful cohorts reaching older age.

Globalisation. Globalisation is increasing economic competition amongst states and reducing the capacity of states to raise resources to meet the demand for public services (because of tax competition and the mobile nature of capital). Globalisation seems to be increasing inequality of earnings almost everywhere (although at different rates depending on the political regime in place) ${ }^{15}$ through so called skills-biased technological change and declining trade union power, both of which reduce the bargaining power of the low skilled and increase the leverage of the corporations and elites. ${ }^{16}$ Globalised capital in a 'financialised' global economy has acquired the power to increase the share of profits going to 
capital and decrease the share going to wages in many countries (since the 1970s). ${ }^{17}$ Global economic competition has also led to major economic restructuring in developed states, with the decline of old industrial sectors and the rise of service industries which become the main source of profit for enterprises. Service industries have generally proved to be slower to improve their productivity than manufacturing industries. One consequence has been that enterprises in the these sectors have been increasingly reliant for their profits not on capital investment and increasing the productivity of labour, but on reducing the costs of labour through various 'efficiency measures.' In a political climate of de-regulation in labour market, this has generally meant increasing the contractual 'flexibility' of labour and reducing the real pay level of the less skilled part of the work force. The has resulted not only in lower real wages for those not in the high skilled jobs, but also in greater casualisation in many jobs. Rates of part-time working, short-term contract working and zero-hour contracts among the adult workforce have all increased in the UK, ${ }^{18}$ although perhaps not to the extent predicted in the 'precariat' scenario popularised by Guy Standing. ${ }^{19}$ However, the current generation of youth have found themselves at the leading edge of these changes in the labour market, ${ }^{20}$ so that they have experienced greater casualisation and a larger increase in unemployment and more wage decline than older age groups. ${ }^{21}$ Gaps between age groups in wages have grown alongside a divergence by age in unemployment rates (although these still remain low in the UK relative to many other developed countries). Some predict that these trends towards reduced real pay and casualisation of labour will spread to the highest-skilled jobs as well, but the older baby-boomer generation will have avoided the worst effects of this. ${ }^{22}$

The 2007/2008 financial crisis and the ensuing recession and austerity dramatised the situation of young people because they were the age group which was hardest hit in terms of rising unemployment and declining real wages. But in reality many of the negative trends in youth opportunities started some years earlier, not only in the UK but also in most other European countries. Youth unemployment and the growing proportion of so-called NEETs-young people not in education, employment or training - has been high in many European countries since the 1980s, with the levels of unemployment reached amongst 18-24s in the early to mid 1980s in Britain, during the early years of Thatcher's monetarist experiment, actually exceeding those of the post 2007 crisis. Decline in real wages amongst young people in Britain also 
preceded the financial crisis. Most important, the financial crisis was the product of the same longer-term trends which have been impacting directly on young people for over a decade. The increasing financialisation of the economy, ${ }^{23}$ and particularly of the property market, which produced the price bubbles and unsustainable levels of lending and debt which detonated the 2007 crisis in the UK, Spain and the USA, has been raising property prices increasingly beyond the reach of young people since the late 1990s. Population ageing has been a marked trend for several decades. The looming crisis in pensions, which will markedly affect the life chances of the current generation of young people as they grow older, was already identified by policy-makers in the 1990s as a likely outcome of population ageing. The economic crisis of 2007/2008 and the following recession, has merely exacerbated these more long-term trends. Young people have been in the front line.

\section{Different Perspectives on the Crisis for Youth}

Most accounts of the crisis of today's youth would broadly agree that the factors above-demographics, globalisation and the recent recession and austerity-are somehow implicated in the changing fortunes of youth. However, they differ in important ways on how these changes are explained and assessed. We can distinguish between four broad types of explanation.

Delayed transitions to adult life. Social psychologists (and others) conduct life course analysis on the basis of longitudinal data on various aspects of the lives of samples from successive cohorts, going back in the UK to those born in 1958 who were 59 in 2017. They are able to show how life course patterns change between generations, how the lives of those now in their 50s were shaped by the circumstances (familial and historical/societal) of their birth and childhood (cohort effects). What they observe in Britain, and in other countries with longitudinal data, is that across successive cohorts, the patterns of youth transitions to adult life have changed significantly. Compared with previous generations, young people today tend to take longer to leave home, gain stable employment, acquire financial independence and to purchase a home. Not unrelated, they are also slower to cohabit or marry, and to start families. ${ }^{24}$ Some research also suggests that this slower maturation process also delays traditional patterns of political engagement, and particularly of voting. ${ }^{25}$ Life course research frequently identifies long-lasting 
cohort effects from the experience during childhood and the formative years of young adulthood on life chances throughout the life course. However, we will not know for many years from the longitudinal data how the far formative years of the current generation have shaped their future lives and the researchers tend not to speculate. They acknowledge that there has been a generational change as regards youth transitions, summed up by the notion of 'delayed transitions', but remain cautious as to whether cohort effects in general will persist through the life course, thus engendering genuine lifetime generational change in life chances, and how far this might persist in future generations.

Political economy perspectives on the crisis of youth. Political economists are generally equally cautious about how far we can talk about wholesale intergenerational decline. Opportunities in each generation are structured by social class, gender and ethnicity. Class and other divisions are reproduced in each generation. The political economy literature shows how inequalities in incomes and have been increasing relentlessly over time in most developed countries since the 1970s. Countries vary in their degree of inequality on each dimension, as a result of different institutional traditions and policy preferences, but the trend is in the same direction in almost all countries.

Rising income inequality is largely attributed to economic globalisation, and the globally dominant neo-liberal policies which have attended it. Earnings have become more unequal, so it is argued, because of skillsbiased technological change, which puts a premium on higher levels skills while reducing the labour market value of lower level skills, ${ }^{26}$ and because globalisation has shifted the balance of power further from labour to capital. Power has shifted due to a combination of weaker unions, de-regulation, unrestrained capital movement, and the overwhelming dominance of mighty multinational corporations. ${ }^{27}$ The increasing global integration of markets and the rapidity and ease with which capital, technologies and ideas flow across borders, allows the transnational corporations, and indeed some smaller enterprises, to rapidly switch different elements of production between countries, as they search for the most favourable environments in terms of wage costs, access to markets and taxation regimes. Low skilled workers, and increasingly more skilled workers, in the most advanced countries, are more and more vulnerable to the threat of offshoring production to areas where labour is cheaper. ${ }^{28}$ This, along with the decline of trade union power and the increasing de-regulation of 
labour markets, gives rise to a continual downward pressure on wages for less skilled work.

Wages at the lower end tend to fall away from the norms in the middle. At the same time, with the spread of complex incentive packages, with payments through obscure share option and bonuses schemes, remuneration amongst the top ten percent, and particularly the top one percent, has been allowed to pull further and further away from median earnings. ${ }^{29}$ The wage distribution is stretched at both ends, raising overall levels of wage inequality. Household income inequality increases, not only through the greater differentials in earnings, but also through taxation policies that reduce re-distribution, and through social trends. Growth in so-called 'assortive mating', whereby couples are more frequently formed between people with similar educational and financial resources, also adds to overall inequality between households in disposable income. ${ }^{30}$

Inequality in wealth is generally greater than inequality in incomes and has also been growing. In his analysis of the long-term evolution of capitalism, political economist Thomas Piketty shows that with the post 1970s slowing of growth in populations and GDP in many countries, returns to capital greatly exceed growth in national output, thus raising the ratio of private wealth to national income. ${ }^{31}$ As private wealth is more unequally distributed than incomes, its relative growth yields dividends that multiply the effects of the already rising inequality in earnings resulting from weaker trade unions, skills-biased technological change, globalisation and stronger corporate elites. As the ratio of private wealth to national income grows to levels last seen in the Edwardian era in the UK, increasing shares of wealth are inherited rather than earned-already typically over 70 percent in western Europe. This will further reduce social mobility for future generations of young people. ${ }^{32}$

Trends in inequality are subject to policy intervention. As Piketty shows, the substantial reduction in inequalities of wealth and incomes experienced in the years between 1914 and 1970 — now reversed-was not just the result of the considerable physical destruction of private wealth during the two world wars, although that may have been a major factor. It was also affected by political decisions to increase public ownership and public spending, which reduced the share of private wealth in the economy, and also by policies on the taxation of wealth, incomes and inheritances, and on minimum wages, explicitly designed to reduce inequality in earnings and household incomes. However, there is also, 
according to Piketty, a logic in the deep structures of capitalism favouring the long-term concentration of wealth and incomes. If inequalities continue to grow, unrestrained by policy, how does this impact on future generations of young people, and where does it take the generational divide?

Wealth is accumulated through the life course, and older age groups inevitably tend to be wealthier than younger ones, even where most wealth is inherited, as now in England. ${ }^{33}$ Wealth is passed on to future generations, and the fortunate amongst younger generations inherit it, reproducing the wealth gaps of the previous generation. As older generations live longer, the privileged amongst the younger generation may have to wait until they are older before they inherit. Others less fortunate may find that their long-living parents have had to spend most of their assets to keep them in old age and have little left to pass on. ${ }^{34}$ For the least fortunate, there was nothing for their parents to leave in any case. Overall one would expect that wealth becomes more unequally distributed over time, amongst adults overall, across age groups, and within each age group. At the same time, if the overall mass of private wealth increases, as Piketty argues, newer generations will accumulate more overall over the life course, and so be wealthier on average than their parents. However, an unsustainable public debt could force policy change whereby new generations had to pay off debts incurred by older generations leading to generational declines in wealth.

Incomes are not passed down the generations, or at least not in the direct way that wealth is, except in the case of potential dividends from assets. Over its life course, a given generation will only be poorer than the previous one, in the aggregate, if real terms per capita earnings are declining over the period or if per capita net incomes decline because of higher taxes. At the present uncertain time economists cannot predict with any certainty whether GDP per capita will fall. However, per capita incomes would fall if real earnings per capita stagnated and a greater proportion had to be paid in tax to fund the costs of ageing and to pay off the public debts accumulated by previous generations.

A generational (over the life course) decline in living standards is possible but not widely predicted, even though per capita income in the UK in 2015 was still lower than in 2007. However, as with wealth, we may see a greater inequality within each age group as well as across age groups, in the latter case because population ageing places increasing burdens on young people wherever they are in the wages hierarchy. This does not 
necessarily equate to the most pessimistic scenario of a wholesale decline in living standards between generations through their whole live course. Nor does it necessarily mean that the gap in earnings of older and younger people will continue to grow, as the generational pessimists tend to assume. But it may nevertheless mean greater disparities and conflicts between age groups alongside the cleavages and conflicts between social classes which run across age groups.

Intergenerational gaps in opportunities and incomes may be largely amongst the least qualified rather than applying to whole generations. Robert Putnam's moving account in Our Kids ${ }^{35}$ of the changes in opportunities experienced by young people in his generation and the contemporary youth in the USA is essentially a story of growing inequality and how it widens the opportunity gap between poor and rich kids in America. The narrative is framed in generational terms, but the analysis is essentially a traditional social class analysis applied to the younger age group. The prospects for many of the less fortunate children in his survey are shown to be much bleaker than for their parents. But the children from wealthier families were generally not doing badly at all, and certainly not worse than their parents. The account does point to greater inequalities between age groups, but it is far from arguing that throughout its lifetime, the current young generation as a whole will be worse off than its parents had been (except possibly spiritually and in terms of depleted social capital).

The 'lost generation' and the 'one-off' ratchet in intergenerational inequality. This is the perspective popularised in accounts of the 'lost generation' and is proffered by at least one detailed research-based study by former Conservative Minister, David Willetts. ${ }^{36}$ This focusses on the differences in opportunities (for work, housing and pensions) of the current generation of young people (born post 1979) and their parents' generation (broadly the baby boomers born 1945-1965). The analysis emphasises the 'unique' characteristics of each generation, in terms of their numerical size, and the particular historical periods during which they were born and lived their adult lives (so looking at both cohort and period effects).

On Willetts' account, the baby boomers were a uniquely fortunate generation. They were born during the years when post-war austerity gave way to increasing economic growth and prosperity but before the major changes in family forms (which to Willetts have had negative effects). They came of age during the 1960s, when jobs were plentiful, 
unemployment was low and incomes were more equal than at any time before or since. ${ }^{37}$ They were the beneficiaries of what many historians now call the 'golden age' of capitalism or, in France, Les Trent Glorienses. ${ }^{38}$ Because of the technological innovations of the pre- and post-war period, professional, managerial and technical employment was expanding, providing career pathways for the still small but expanding cohorts of higher and further education graduates. There was more 'room at the top' and the changing shape of the class structure thus allowed increasing social mobility in both absolute and relative terms. The baby-boomer generation (and particularly the males who still formed most of the graduate population) benefitted from rising wages, and subsequently from even more rapidly rising household incomes as female employment increased and dual earning households became the norm. They prospered further on account of other favourable conditions for acquiring wealth. They bought their homes when housing was still affordable and saw their mortgages paid off relatively easily as inflation reduced the real value of their debts in the 1970s. As house prices began to rise rapidly in the 1990s, they often found themselves in middle age with valuable housing assets which they could use as collateral for the increased borrowing which became the basis for their growing consumer spending.

The older baby boomers managed to avoid the worst of the negative effects of globalisation. By the time that major economic restructuring manifested itself in the shake up of working practices from the 1990s, with the job insecurities that attended de-regulation and flexible working, baby boomers were advanced in their careers and well ensconced in their jobs, thus better protected than younger workers. As the boomers reached retirement, many were still able to benefit-just-from generous final salary pensions schemes, and a public health service that was stillmore or less-intact. But the post-war cohort not only benefitted from the good timing of their birth. They were also a very large generation, which came to wield great political clout. As they grew older, government policies were increasingly swayed by the strength of the 'grey vote' and favored their age-based interests.

By contrast, according to Willetts, the subsequent generations, and particularly the Millennials, born in the 1980s and 1990s, were uniquely unfortunate, both historically and demographically. They were a much smaller cohort, who would have little electoral power when they came of age. Their transitions to adult life were made more 
difficult because of the socio-economic changes of the years from the 1990s when the effects of globalisation began to kick in. Those with few qualifications found it harder to get jobs, since the low skilled jobs were being offshored or downgraded in terms of remuneration and job quality. For the growing contingent of graduates, wage returns to qualification began to diminish-or at least to become more polarized and uncertain. ${ }^{39}$ Precarious jobs were becoming more prevalent across the board due to the effects of labour market de-regulation but particularly amongst young people, as we will show in Chap. $3 .{ }^{40}$ Chances of wealth accumulation were also reduced for this generation (unless they were lucky enough to inherit), partly because rocketing rents made saving difficult, and especially because sky-high house prices made it nearly impossible for most to get or pay a mortgage. These young people were hardest hit of the generations by the financial crisis and ensuing austerity and found it much harder than the boomers to make their way in life. Looking into the future their prospects looked equally bleak. Many would be saddled with much higher personal debt than their parents, due to higher education tuition fees and huge mortgages, and looked forward to paying increasing taxes to pay off the public debt run up by the boomers, and to finance the pensions and health care costs of the growing population of retirees. They would be unlikely to benefit themselves when older from the generous pensions and high levels of spending on health care experienced by their parents.

The lost generation narrative tends to ignore intra-generational inequalities, the differences within generations, but it has certainly brought to public attention to the growing intergenerational inequalities in our society. However, it is principally a contrast between two generations, one which is seen to be uniquely favoured in terms of demographics and historical events, and the other the opposite. Less thought is given to the longer-run structural changes which are occurring and which may shape intergenerational relations permanently. The focus is on relatively short-run historical trends and the effects of successive change in birth cohort sizes. One extrapolation from Willetts' account would be that as the current younger generation carries its disadvantages through to old age, and subsequent generations inherit the new economic and social status quo, lifetime generational gaps will again begin shrink. An awkward transitional era of growing intergenerational inequality will pass, as future generations each experience the same reduced opportunities in terms of secure jobs and house buying and the same diminished safety nets from 
pensions and public welfare provision. As the larger birth cohorts born post 2000 come to adult life, the disproportionate political power of the grey (baby-boomer) vote will diminish. An intergenerational 'business as usual' returns, as social inequalities, across all age groups, resume their role as the underlying cleavages in society.

A new long-term dynamic of growing intergenerational inequality. This perspective shares much with the account above, with the starting point likewise being the growing gap between the opportunities of the current generation of young people and their parents' generation when they were young. However, the way it analyses the reasons for the growing generational gap is different and points towards a more long-term tendency towards continuing increases in intergenerational inequality over time. In the account by Howker and Malik, co-founders of the campaigning Intergenerational Foundation, a different analysis is provided of the cause of the current divergence in generational fortunes. ${ }^{41}$ Howker and Malik are less interested in the size of the different generations and how this may affect political power and policy. They also wish to avoid stigmatizing the baby boomers who they don't see as uniquely selfish or responsible as a generation for the plight of young people today. Their contention rather, is that there has been a radical culture and value shift since the 1980s which is the root cause of the policies which have exacerbated intergenerational divisions. This value shift-which is broadly characterised as increasing individualism-is seen to have its origins in the 1960s, when the young baby boomers were recasting cultural politics, and is thus easily equated with this generation. But it became embedded in the 1980s when the entire political culture was re-caste through the Thatcherite revolution, with its emphasis on rolling back the state, freeing up the market, de-regulation and the weakening of collective organisation (particularly of labour). This went far beyond a generational shift in political and cultural values (with a particular cohort in the vanguard), since it reshaped society as a whole, affecting all age groups more or less equally.

While Willetts maintains that this individualism is primarily associated with the boomer generation who had more 'liberal' attitudes than preceding or succeeding generations, writers such as Georgia Gould dig deeper into the attitudes of today's young, reminding us that they are incontrovertibly 'Thatcher's Children,' formed in the ideological crucible of Conservative and, later, New Labour, neo-liberalism. ${ }^{42}$ At the political level, the Malik and Howker account castes neo-liberalism as the 
main culprit. It has been the policies of neo-liberalism which have been disproportionately disadvantageous to a particular generation of youth because they happened to be in the front line of the changes. However, underlying the new market politics, was a deeper cultural shift to a new individualism that not only sanctified 'free choice' and the satisfaction of immediate individual wants above all, but which portended a new kind a 'presentism' in which the future (and future generations) were subsumed to the needs of immediate consumption and short-term economic growth. ${ }^{43}$

In short, this new culture cared little for investing in the future. Rather, policies were adopted which benefitted the present consumer, property owner and shareholder, whatever the damage to future generations. Howker and Malik note the squandering of the proceeds from North Sea oil; the privatisations which sold off the publically-owned 'family silver' to enrich what turned out to be a rather small group of current shareholders; the selling off of council houses which enriched many of one generation of tenants at the expense of future generation of home-seekers; the Private Finance Initiative (PFI) deals used to shore up the infrastructure (of schools and hospitals) at an inflated cost to be paid by future generations; the post 2008 bail-out of the banks, estimated at $£ 1.16$ th at its peak in $2010,{ }^{44}$ to be paid for by future generations of taxpayers, and the general tendency to acquiesce in-and even encourage-the building up of debts which would literally mortgage the future.

Most importantly, they argue, governments have consistently encouraged the escalation of house prices, not only to ensure the political loyalty of (older) homeowners, but also to maintain economic growth in an economy with flagging demand and poor competitiveness in most sectors baring finance. Recent research shows that almost all of the increased demand which kept the UK economy growing during the 'boom' years of the new Millennium can be accounted for by the growing volume of equity released from mortgages, made possible by the escalating values of homes. This government-engineered hike in property values has led to a wealth transfer of historic proportions from future generations of home buyers to current generation of home owners.

Another worrying manifestation of this extreme 'presentism', noted also by Willetts, is the long-term decline in saving amongst UK families, far in excess of trends in most comparable countries. Between 1990 and 2008 the proportion of household income saved dropped steadily from 3.9 to -4.4 percent in the $\mathrm{UK}$, compared with a drop from 7 to 1.8 percent 
in the USA; from 12.9 to 11.4 percent in Germany; and a rise from 9.4 to 11.9 percent in France. ${ }^{45}$ Howker and Malik say little about climate change but to many-and particularly young people - the failure of the current generation of politicians to deal with global warming represents the most egregious case of sacrificing the future to the present.

What is distinctive about the account here is its deep pessimism. Howker and Malik see the new individualistic presentism not as a pathology of a particular generation but as the new cultural norm. Its implications are deeply depressing because if selling the future for the present is a long term trend, conditions can only get worse for each successive generation, so long as there remains anything left to sell and a sustainable planet to inhabit. They say little about demographic trends but one reading of these supports their case. If the most important demographic forces are not the fluctuations in successive cohort fertility rates, as in Willetts' account, but rather continuing ageing of populations, due to ongoing increases in life expectancy, then widening intergenerational divides can be predicted well into the future.

\section{Changing Opportunities in Different Domains: Education; Employment; Housing; Wealth; Benefits and Political Representation}

The following chapters provide an overview of changes in opportunities for young people in the key domains which most affect life chances: education, employment, housing, wealth and welfare distribution and political power. As we will see, there are shifting patterns of opportunities in each domain, but each manifests its own dynamic. The evidence for longer-term structural shifts, as opposed to temporary dislocations, is stronger in some areas than others. Where there is evidence of a longer-term structural shifts, what is the nature of the change in intergenerational patterns of inequality? Is the growing gap just between age groups, between the young and older adults, and if so will this persist over time so that future young people remain equally disadvantaged relative to older age groups? Or is there a ongoing cohort effect amongst current young people whereby they carry their disadvantages as young adults through the life course, suggesting a lifetime reduction in opportunities compared with the previous generations? Does this point 
towards a future where successive generations face poorer life course opportunities than the last?

Open Access This chapter is licensed under the terms of the Creative Commons Attribution 4.0 International License (http://creativecommons.org/licenses/ by $/ 4.0 /$ ), which permits use, sharing, adaptation, distribution and reproduction in any medium or format, as long as you give appropriate credit to the original author(s) and the source, provide a link to the Creative Commons license and indicate if changes were made.

The images or other third party material in this chapter are included in the chapter's Creative Commons license, unless indicated otherwise in a credit line to the material. If material is not included in the chapter's Creative Commons license and your intended use is not permitted by statutory regulation or exceeds the permitted use, you will need to obtain permission directly from the copyright holder.

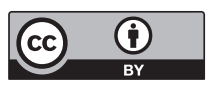

